\title{
BRICOLAGE IN ORGANIZATIONS ${ }^{1}$
}

\section{MIGUEL PINA E CUNHA}

Faculdade de Economia Universidade Nova de Lisboa

Rua Marquês de Fronteira, 20

1099-038 Lisboa; Portugal

Tel: 351-212 822725

Fax: 351-213 873973

mpc@fe.unl.pt

\footnotetext{
${ }^{1}$ I would like to thank Manuela Faia-Correia, Giovan Francesco Lanzara and Dusya Vera for their
} helpful comments on this paper. I gratefully acknowledge support from Instituto Nova Forum. 
BRICOLAGE IN ORGANIZATIONS

\begin{abstract}
Theories of management and organization have traditionally overlooked the concept of bricolage. Focused on the rationality of resource allocation, scholars have missed the relevance of the skill of "inventing” resources from available materials. Changes in the nature of competition are, however, stressing the importance of speed and change as competitive factors in shifting environments. In these environments it may be impossible to search and wait for the presumably adequate resources. Bricolage, therefore, may be a relevant practice in these environments. This article discusses the concept of organizational bricolage by asking such questions as: What is bricolage? Why is bricolage a relevant practice? Why is bricolage so often ignored? How can it be facilitated?
\end{abstract}

Keywords: resources, resourcing, bricolage, improvisation. 
Historically, the competent manager has been portrayed as someone who articulates a strategy and rationally allocates resources to facilitate its implementation. The skill of planned resource allocation has been at the heart of the management discipline since its inception (Taylor, 1911). The mechanical roots of the field (Shenhav, 1999), with a focus on stability and uncertainty reduction, help to understand why this description emerged in the first place. The domination of strategic thinking by the industrial organizational paradigm has reinforced this assumption (Porter, 1981), by highlighting the structural, and thus stable, nature of resources and competition. Recent theories, however, have presented the resource management process in different colors. Pfeffer and Salancik (1978) in their resource dependence perspective, highlighted the symbolic and political processes involved in resource attraction. Research on dynamic capabilities suggests that modularity increases the set of recombinant opportunities, which helps to match organizational resources with emerging competitive needs (Eisenhardt and Martin, 2000; Galunic and Eisenhardt, 2001). Eisenhardt and Brown (1999) emphasized the importance of patching, i.e., the strategic process by which managers remap businesses to market opportunities. Patching invites managers to rapidly reconfigure resources in order to address ephemeral market opportunities. Weick (2003, p.69) associated organizational reliability with bricolage: "positive organizing (...) occurs concurrent with whatever unexpected events occur using tools that themselves were unexpected recombinations of existing repertoires.” In other words: more than a pre-ordained, repetitive, rational and stable process, resource management can be portrayed as "resourcing": a complex, dynamic and exploratory process, characterized by resource mutability in a given context (Feldman, 2004). The relevance of a dynamic view of organizational resources is also highlighted by Teece and his colleagues when defining dynamic 
capabilities as “the firm's ability to integrate, build and reconfigure internal and external competences to address rapidly changing environments” (1997, p.516). The capacity to reconfigure resources may be a component of dynamic capabilities. New concepts may thus be necessary for developing a more realistic understanding of the dynamics of organizational resourcing. As advanced by Feldman (2004, p.300), "the same quality or asset used differently becomes a different resource and energizes different schema.” Hence the need to view resourcing as a complement to the notion of resources.

In line with the logic of dynamic capabilities, if one takes ambiguity and flux as irrevocable features of organizational environments, a planned approach to resource allocation may not be adequate as an explanation. People facing difficult and uncertain situations, may have to use whatever resources they have at hand to reach their goals. This explains why bricolage tends to be used in critical situations (Rerup, 2001; Gonzales, 2003). In these situations people are urged toward "using the world, obtaining what they need, doing what they have to do” (Gonzales, 2003, p.274). In other words, they have to use their skills of bricolage. The potential relevance of bricolage for problem solving has long been recognized. Homer’s Odyssey provides a classical example of the potential benefits of bricolage. As Gabriel (2003, p.623) remarked: “Odysseus is a paragon of bricolage. Unlike so many of today’s managers, Odysseus never complains of inadequate resources. Making do with whatever resources are available to him, he is capable of redefining useless materials into useful ones and of redefining his objective in line with the resources available.” This perspective is aligned with the Austrian view of the strategic process, which sees competition as built on entrepreneurial action and energized by waves of creative 
destruction. As noted by Jacobson (1992), “entrepreneurship is action that successfully directs the flow of resources toward the fulfillment of consumer needs. Alertness to opportunities is the hallmark of entrepreneurs” (p.787). In entrepreneurial markets, improvisational real-time action and bricolage may be viewed as processes of major importance: they help firms co-evolve with their environments. Scholarly attention to bricolage is, however, the exception rather than the rule. Baker, Miner and Esley (2003, p.270) noted that “the concept remains extremely underdeveloped.” This article contributes to the development of the bricolage concept. It contrasts planned resource allocation with bricolage. The paper adds to the literature by showing how valuable the skills of bricolage may be for organizations competing in fast changing environments. This recognition has not been afforded up to now because bricolage looks "messy" in the context of the dominant structural paradigm. However, in hypercompetitive environments, success often thrives on speed and capacity of response (D’Aveni, 1994). In these environments, the need to improvise and the recognition of knowledge management as a creative exploration of materials and contexts (Montuori, 2003), are paving the way for a re-appreciation of bricolage as a potentially virtuous practice, or as a process underpinning such views as dynamic capabilities or strategizing.

Considering the stated goals, the article has been organized as follows. It starts with the definition of bricolage. Then I contrast resource management in two modes: under a design-precedes-execution mode and as bricolage. The discussion next moves to the relevance of bricolage as an organizational concept. Finally, I present some possibilities for cultivating bricolage in organizations. To facilitate practical understanding of the concept, some examples of the practice of bricolage are offered 
in the Appendix. The paper contributes to the organizational literature in several ways. First, it clarifies the meaning of organizational bricolage, a concept that has seldom been addressed in the organizational literature. Second, it suggests that if new competitive markets require dynamic concepts, bricolage may be one of such concepts. Third, it presents some conditions for the occurrence of bricolage in organizations. In summary, I propose that bricolage is not a deviation from "proper" management but a necessary practice for our organizations.

\section{THE CONCEPT OF BRICOLAGE}

Bricolage can be defined as the invention of resources from the available materials to solve unanticipated problems. It is a local, contextual, and sudden process which, as remarked by Ciborra (2002), cannot be thought of outside the specific situation where it appears. It may be thought of as a form of practical intelligence, in the sense that it manifests itself in how people organize their everyday activities to accomplish their goals and how they reorganize to adapt when something goes awry (Wagner, 2000). Practical intelligence may therefore refer to how people reorganize their resources in the face of unexpected circumstances. Resources have been defined as "all assets, capabilities, competencies, organizational processes, firm attributes, information, knowledge and so forth that are controlled by its members and that enable the firm to conceive of and implement strategies that improve its efficiency and effectiveness” (Barney, 1997, pp.142-143). Eisenhardt and Martin (2000, p.1107) defined them as “those specific (e.g., specialized equipment, geographic location), human (e.g., expertise in chemistry), and organizational (e.g., superior sales force) assets that can be used to implement value-creating strategies". Considering the breadth of the meaning of "resources", bricolage can take many forms, from finding new uses for 
existing resources, to expanding and reinforcing social networks (please consult the Appendix for illustrations of bricolage).

A person engaging in bricolage is called a bricoleur, someone "who makes things work by ingeniously using whatever is at hand, being unconcerned about the 'proper' tools or resources” (Thayer, 1988, p.239). The terms bricolage and bricoleur come from Levi-Strauss (1966) and were imported to the organizational field by authors such as Karl Weick, Claudio Ciborra and Giovan Francesco Lanzara. There are radical differences between the bricoleur and the rational resource planner, as commonly portrayed in the literature: while the bricoleur departs from the event to build a structure that makes him/her able to solve the problem (how may the event be approached with the current conditions), planners are expected to act the other way around, i.e. to depart from a structure (knowledge of the situation and a diagnosis of necessary resources) and then apply it to the event (what resources are necessary to deal with the situation?). Bricolage can be practiced both individually and by teams of people. It can be both used at the managerial and operational levels. In this sense, when occurring at the top, it can have a strategic impact. This strategic impact may happen, as observed by Lanzara (1998, 1999), because managers may prefer to start changing structures by means of bricolage rather than by paying high sunk costs and committing themselves too early to radically new structures (see episode 1 in the Appendix). Bricolage may also play an important, although neglected, role in institution building. As observed by Lanzara (1998, p.28) "institution building often occurs not on the ruins but with the ruins of the old regime, as available resources are deployed to respond to emerging practical dilemmas” (italics in the original). 
Bricolage has been previously defined as "a process of sensemaking that makes do with whatever materials are at hand" (Weick, 1993, p.351) or "to use whatever resources and repertoire one has to perform whatever task one faces” (p.352). Thus, bricolage refers to "mind in action” (Scribner, 1986, p.15), involving contextual embeddedness and instrumental thinking. It is possible to hypothesize that the use of bricolage tends to be avoided in the "managed organization", but erupts in the “unmanaged organization” (Gabriel, 1995). In other words, bricolage is one of those practices that are often only admitted when personal defenses regarding the formally "proper" job execution are less vigilant. On the contrary, in the case of the "unmanaged organization", as will be discussed below, the bricoleur is often portrayed in a positive light, as a resourceful and imaginative trickster. Orr's (1996) description of copier machine technicians provides an eloquent example of the importance of bricolage and improvisation in the constitution of professional identity, in opposition to the formal job description.

\section{RESOURCES AND RESOURCING: DPE AND BRICOLAGE}

In this section, I contrast two understandings of resource management in organizations. In the first case, managers are expected to design a strategy and then to execute it. Baker et al. (2003) labeled this mode as “design-precedes-execution” (DPE). In principle, and according to the prevailing logic of rationality, organizations "should" work according to this model, since rationality means thinking before acting. However, research is indicating that strategy is often the result of opportunity, emergence and exploration (e.g., Mintzberg \& McHugh, 1985). For example, suddenly an opportunity is identified and grabbed by an entrepreneur that recognized its potential (Shane, 2000). This corresponds to a second mode, or to a strategic logic 
of opportunity (Lengnick-Hall \& Wolff, 1999), where organizations need to react to opportunities with the available resources rather than with the ideal ones. In this logic, bricolage is crucial. In the remainder of this section, I contrast the two modes of resource management as DPE and bricolage.

Resource management in a DPE logic. We can think of organizations as bundles of resources, and as such competing on the basis of the resources they own. Resource management is then a crucial task. Hence the interest of both scholars and practitioners in this topic. Scholarly interest resulted for example in a resource-based view of the firm (Wernerfelt, 1984), which suggests that companies should manage and leverage their resources to cultivate competitive superiority. From a resource base view, the firm itself can be considered as a bundle of tangible and intangible resources. In another perspective, practitioner interest is at the root of the popularity of enterprise resource planning systems (Mabert, Soni and Venkataramanan, 2001), tools designed to integrate business processes and systematically manage the firm's resources. Therefore, the resource management process is a fundamental business activity. Competent resource management may improve efficiency through the streamlining and perfecting of organizational routines (Taylor, 1911). It may diminish resource dependence through the recognition and control of critical sources of uncertainty (Pfeffer and Salancik, 1978). It can facilitate strategic renewal by means of the introduction of mechanisms that facilitate the redistribution of resources to more promising strategic intentions (Lovas and Ghoshal, 2000) or to complement existing and emerging businesses (O’Reilly and Tushman, 2004). 
The analysis of the resource management process needs, however, to direct more attention to how organizations dynamically develop and take advantage of their resources rather than simply assuming that VRIN (valuable, rare, inimitable, nonsubstitutable) resources lead to sustainable competitive advantage. Several issues have been tackled while studying the relationship between resources and organizations: resource acquisition, dependence and control (Pfeffer and Salancik, 1978), resource reconfiguration (Eisenhardt and Brown, 1999) and resource advantage (Lippman and Rumelt, 2003). A limitation of some research dealing with the management of resources, is that it adopts a purely DPE perspective, focusing on the pool of resources owned or controlled by the firm, instead of analyzing the process of resource deployment, development, utilization and degradation, as well as resource invention through bricolage. Next, I describe the process of bricolage.

Resource management as bricolage. A perspective which complements the DPE mode may be found in bricolage. Nohria and Berkley (1994, p.133) described effective managers as bricoleurs: "They play with possibilities and use available resources to find workable solutions.” When facing unexpected and relevant issues both problems and opportunities - they need to improvise solutions, which means that they have to act deliberately and unexpectedly (Moorman and Miner, 1998) and resort to whatever materials they have. The well-known emergency situation aboard the Apollo 13 spaceship provides an eloquent example of a serious situation in which problems needed to be solved with the available resources (see episode 2 in the Appendix for a description of this case). Fortunately, most situations requiring the skills of bricolage are less dramatic. 
Bricolage is about resource invention, requiring a "contingent, inductive and playful” (Kallinikos, 1998, p.179) approach to work. It refers to doing what one has to do with the resources available at a given moment. These may not be the "optimal” resources. Probably they are not. If resource allocation involves the creation and distribution of adequate resources, bricolage is about minimal resources, or about making the best out of the available resources.

The activities of bricolage seem more likely to occur when impromptu action is required for facing concrete and unplanned environmental conditions (Cunha et al., 2003). It is these conditions that, by rendering operating plans inadequate, stimulate the kind of temporary "occasional plans" ("occasional” here meaning adapted to the circumstances [Scribner, 1986]) activated by improvisational practice. In this type of situations, when the recourse to the most recommended resources is not possible, and when problems have to be tackled with the existing people, information and materials, managers need to create contexts that facilitate proficiency in the practice of improvisation and bricolage (episode 3 in the Appendix).

The comparison between the characteristics of the previous two modes of resource management indicates that DPE is close to "theoretical thinking”, whereas bricolage is closer to "practical thinking”, to use the notions proposed by Scribner (1986). This suggests that the concern of the bricoleur with practical, day-to-day, opportunistic behavior, gives place, in the case of the planner, to abstract, complex and symbolic thinking processes, that do not deal opportunistically with the practicalities of the present, but are mainly characterized by analysis and abstraction. Bricolage deals with the concrete facts of everyday life, most often with no immediate visible impact on 
the organization as a whole and, consequently, apparently having a non-strategic impact and, fundamentally, an operational focus - but as observed by Lanzara (1998), incremental changes can produce radical innovations. The bricoleur is someone who believes that experience is the "firm database" (Berry and Irvine, 1986) and who learns how to invent resources from a deep knowledge of the materials and the current situation.

The process of bricolaging thus involves not only the collection and reorganization of available materials, but also the creation of new tools from old materials. It is in this sense that the bricoleur is someone who works with "the hands". By "handling" the materials - experimenting, reframing, recontextualizing, imagining, manipulating the bricoleur develops a "hands on" knowledge of resources, which may or may not turn out to be valuable. Bricolage is a practical, experiential approach that is developed by watching and listening to others, and by trying and experimenting for oneself. The above discussion does not intend to suggest that one of the two forms is superior to the other; instead they should be taken as complementary: the rational management of resource allocation does not preclude the need for skillful bricolage and vice-versa, as empirically observed by Baker et al. (2003).

In summary, the manager's role may consist of the accumulation, categorization, development and utilization of organizational resources over time (Moingeon et al., 1997), but also in piling, disorganizing, reorganizing, testing and trying unorthodox uses of organizational resources over time. Planned resource allocation and bricolage may therefore be viewed as "two parallel modes of acquiring knowledge" that require "the same sort of mental operations and [that] differ not so much in kind as in 
different types of phenomena to which they are applied” (Levi-Strauss, 1966, p.13). Baker et al. (2003) complemented Levi-Strauss' argument by showing that the same managers resort to both modes of action at distinct times, according to need and opportunity.

\section{THE PROCESS OF RESOURCING}

In this section, I discuss the process of bricolage. Two levels are considered: the individual and the organizational. At the individual level, two types of agents will be referred to: managers and non-managers. Considering the case of managers within a logic of functionalist rationality, their job would consist of such activities as planning, organizing, staffing, directing and controlling (Daft, 1999). Managers, therefore, are agents of prediction and rationality: they monitor the environment, set a strategy, allocate resources, develop other managers, build the organization, and oversee operations (Pearson, 1989). Contradictory evidence, however, has been advanced by such authors as Mintzberg (1973), Watson (1994) and Bruch and Ghoshal (2002), who pointed out the fragmented nature of the managerial work, as well as the need for managers to tackle unexpected problems and to allocate and reallocate resources according to unplanned circumstances. Despite the possible realism of the bricolage perspective, management is generally portrayed as an abstract rather than as a practical activity. Under the prescriptive view, the managers' job would consist of finding and assigning the resources needed by the organization. Managers would voluntarily engage in activities of resource allocation in order to reduce external dependence (Pfeffer and Salancik, 1978). From this, I derive a first proposition for further advancement of knowledge on organizational bricolage: 
Proposition 1: Managers present themselves according to a DPE mode: they tend to characterize their profession as involving planned resource allocation rather than bricolage.

However, according to Weick (1993), resource dependence may be more myth than reality: confronted with the lack of resources (adequate or needed), diligent managers may invent resources from available materials. Resource creation is taken by Gildner (1984) as a distinctive characteristic of the entrepreneur: "The entrepreneur is not chiefly a tool for markets, not a scout of opportunities, but a developer of opportunities, not an optimizer of resources but an inventor of them” (pp.16-17). I argue that this view may extend to managers working in mature firms as well as to non-managers. In the case of non-managers, in particular, bricolage may be seen through different lenses. Practical knowledge of resources may be something valuable in many professions, especially in technical and manual ones, those where people work with tangible rather than symbolic and informational resources. Flexible use of materials may help workers in developing creative solutions to unexpected problems. That is why the technicians in Orr's (1990) investigation viewed themselves as troubleshooters rather than executors of instructions formalized in manuals. Being a troubleshooter was a source of pride, professional identity and peer admiration. Consequently, technicians, as a community of practice, viewed themselves as improvisers and bricoleurs. Troubleshooting was both a source of professional identity and resistance to organizational control (Contu and Willmott, 2003). More than order takers, these professionals presented themselves as skillful improvisers, mastering the art of bricolage. "Troubleshooting” refers, in this case, to the capacity to 
improvise solutions on the spur of the moment, with the available materials. From this I derive the following propositions:

Proposition 2a: Despite their own description as rational resource planners, managers sometimes act according to a bricolage mode.

Proposition 2b: In some professions, people incorporate bricolage skills in their professional identity: they tend to view themselves as bricoleurs rather than planners or order takers.

At the organizational level, activities of bricolage are likely to be triggered when situations arise that require novel and expeditious ways of tackling issues. These situations can be characterized by the presence of two causes: unpredictability of events and the need for fast action. Unpredictability fosters bricolage because it neutralizes existing plans and makes current resource distribution obsolete, by introducing unexpected gaps between plans/procedures and real events. The need for rapid action stimulates bricolage by inhibiting the modification of existing plans as well as forbidding the elaboration of new ones. Managers need to plan but also to improvise, i.e. to make do with available resources without a plan (Cunha, Cunha \& Kamoche, 1999).

The improvisation-bricolage relationship can be adequately captured in the following citation: "Faced with the task, say, of repairing a faulty machine he [the bricoleur] looks over the material at hand and improvises a solution” (Gardner, 1973, in Berry and Irvine, 1986, p.272). As Gardner makes clear, bricolage is frequently embedded 
in improvisation: it is because one needs to solve a problem in real-time, that there is no time to look for optimal resources. If one does have the time to plan, then he or she may anticipate what the best resources are and how they can be acquired and utilized. The manager as improviser, strategizer and bricoleur is someone who links the past and the future through a great awareness of what, when, why and how resources have been used before. The term "experience" refers to the process through which the experienced manager develops skills which allow her/him to act according to personal experience rather than to formalized explicit knowledge (Vera and Crossan, 2004). That is why experts can be more involved in bricolage than novices. Hence:

Proposition 3: Bricolage is more likely to be practiced by experienced rather than by inexperienced people.

In terms of outcomes, the bricolage mode of operation has not been demonstrated to be worse than the DPE mode, nor is it demonstrated to be better. In their analysis of the development of wind turbines in Denmark and the US, Garud and Karnoe (2003; episode 4 in the Appendix) showed how the Danes were able to develop a more successful design with a technically inferior solution due to their skills of bricolage, and namely to their capacity to build on and to upgrade existing knowledge incrementally, by means of interaction. In the same vein, Cunha et al. (2003) showed how technically simple but effective solutions were used to solve communication problems between different sub-teams of a cross-national product development team. Baker and his colleagues (2003) suggested that relying on existing - even if not completely adequate resources - may facilitate problem solving. As such: 
Proposition 4: Bricolage may lead to adequate solutions when flexible even if simple resources are used.

To summarize, in this section I discussed how planned resource allocation and bricolage may be conceptualized as complementary organizational processes. The Newtonian logic pervading organizational thinking (e.g. Tsoukas and Knudsen, 2003) may have contributed to the unquestioned assumption of the superiority of "rational management of resources”, but, in practice, organizations may need both skills. In this section, I developed some general propositions regarding the process and practice of improvisational bricolage, which may be tested in future research. In the next section, I advance some possibilities on how organizations may cultivate and develop the skills of bricolage among its members.

\section{CULTIVATING BRICOLAGE}

If bricolage is potentially relevant to organizations, as I have discussed in the previous section, how can firms cultivate it? Existing literature suggests that two elements appear as particularly relevant for this purpose: (1) the creation of improvisational cultures; and (2) the adoption of invisible, third-order control mechanisms. Other facilitating elements should, however, be identified, including strategic factors (e.g., prospective cultures) and organizational designs (e.g., adhocratic configurations).

Improvisational cultures. Pro-improvisation cultures can basically be described as those that value an aesthetics of imperfection (Weick, 1999), i.e., that attach a positive value to learning experiences, be they successful or unsuccessful. A pro-improvisation culture is one which stimulates experimentation, the willingness to take risks, and 
which sees errors as failures of reach but also as opportunities to gain information which may not be easily accessible by other means (Sitkin, 1992). There is anecdotal evidence suggesting that individuals are more willing to improvise and to engage in the practice of bricolage when they feel empowered to take action (Carlzon, 1985) and feel psychologically safe (Edmondson, 1999). In this case, they will use whatever materials they have to solve problems on the spot. In less empowering cultures and psychologically harsh environments, people will instead defer to the hierarchy, to established routines and to risk-free procedures, adopting defensive behaviors. Therefore:

Proposition 5: Bricolage is more likely to occur in organizational cultures that stimulate individuals to improvise in a context of empowerment and psychological safety.

Invisible controls. Another structural characteristic that may facilitate bricolage is the absence of direct and visible mechanisms of control and the presence of indirect, invisible ones (Perrow, 1996; Sewell, 1998). Visible control mechanisms, such as the giving of orders or control by norms and procedures, hinders spontaneous behavior and discourages the non-traditional use of materials because it directs employee behavior, reducing the sense of mastery and autonomy necessary for bricolage to occur. Accepting a common purpose and sharing a set of values, combined with a culture of initiative, constitutes a powerful but non-obtrusive control mechanism, which seems to be adequate for bricolage to flourish. In this type of organizational context, people will feel more willing to experiment with new uses of well-known materials. 
One possibility for operationalizing invisible unobtrusive controls is via minimal structures or semi-structures. Minimal structures are structures that combine freedom and control. To achieve these contradictory requirements simultaneously, minimal structures define the boundaries of people's behavior by specifying a small set of “big” rules, namely goals, responsibilities and deadlines (Kamoche and Cunha, 2001). How the goals will be reached is something left to the discretion of individuals and teams. The notion of minimal structures has been found to be associated with the capacity of organizational members to be creative without running the risk of losing coordination (Brown \& Eisenhardt, 1997). Minimal structures may facilitate bricolage because they create a space for improvised exploration within established boundaries. If we take improvisation as the conception of action as it unfolds drawing on the available resources, the connection between minimal structures and bricolage can be easily established; minimal structures create a space for exploring novel uses of materials. In contrast, when organizations rely on stable routines and tight structures and controls, they invite their employees to follow established procedures and to use resources in predetermined ways rather than inviting them to be creative and to engage in exploration, improvisation and bricolage (Eisenhardt and Martin, 2000). Hence:

Proposition 6: Bricolage is more likely to occur in minimally structured organizations that stimulate personal autonomy and freedom. 
A state of discontent with contemporary organizational research has been voiced by several authors (e.g. Sievers, 1993). Such discontent may be due to, among other things, what has been qualified as the disembodied and lifeless nature of a substantial part of the organizational literature, something which is legitimized and perpetuated by a research paradigm that features predictability and certainty. Going back to Katz and Kahn's (1978) classical text, the roots of this disembodiment can be traced to the lack of study of the "real social world”. This separation between social systems reality and myth making ideology, would lead to biased perspectives on management. One of the results of the difference between "real world" practices and their formal, scientific representations, is the discourse of the manager as resource planner, and the lack of analysis of manager as bricoleur. Sometimes managers behave as rational resource planners under a DPE mode, but at other times they do not. A discussion of management as bricolage will then be useful to add to the group of descriptive, unconventional and non-hegemonic approaches referred to by Thayer (1988). Even the meaning of "resources" often refers to abstract and grandiose assets or skills (Collis and Montgomery, 1995) which can only be understood and managed by highly trained people, assisted by sophisticated technologies. Bricolage adds an element of realism to the analysis of the resourcing process and complements the existing understanding of the management of organizational resources. As put forth by Weick (2004, p.664), "People are not very good in forecasting. (...) then it makes more sense to invest in generalized resources that can fit in a variety of new environments than in better models of forecasting.” If forecasting is difficult, bricolage may be necessary.

In this work, the concept of bricolage as organizational and managerial practice was discussed. I explored why bricolage may be more important than is usually 
acknowledged; why every manager is, by chance or by choice, a bricoleur; why bricolage is not a defective version of effective resource management. Management is a profession that simultaneously employs fairly high orders of abstraction and yet is pervaded by concrete practice, which suggests the need to understand both the processes of resource planning and bricolage. Until now, organization and management scholars have concentrated on abstract thinking, almost ignoring the practical intelligence involved in such activities as strategizing (Jarzabkowski, 2004), learning (Crossan and Berdrow, 2003), improvising (Cunha, Kamoche and Cunha 2003), intuiting (Mintzberg and Westley, 2001), rushing (Bruch and Ghoshal, 2002), listening (Alvesson and Sveningsson, 2003) and bricolaging. The blind spot of organizational bricolage may be a weakness, especially in the face of fast changing environments, where the capacity to improvise is being reevaluated as a proper research subject (Brown and Eisenhardt, 1997) and as a practice with functionally adaptive properties, not as an inconsequential, if not dysfunctional, deviation (Lewin, 1998, p.539).

The paper has limitations. The most relevant has to do with the fact that the propositions advanced here are more grounded on anecdotal evidence than on solid empirical work or systematic observation. But this weakness is a consequence of the lack of attention devoted to bricolage until the present. It is because research on bricolage is scarce that organizational researchers ought to investigate it. A second weakness, to be further addressed, refers to the close relationship between the concepts of bricolage and improvisation adopted in this text. Some authors (Baker et al., 2003) have suggested that bricolage can be combined with planning, a finding to explore in future research. Here, however, we took bricolage as mainly occurring in 
tandem with improvisation as a means of dealing with unpredicted and unplanned circumstances. Different manifestations of bricolage should then be investigated. A difficulty involved in the study of bricolage refers to the problems with spotting instances of bricolage in ongoing organizational processes. It is meaningless to study bricolage ex post facto, due to retrospective justification and to the actors' reconstitution of previous organizational circumstances.

I conclude by revisiting Berry and Irvine’s (1986) paper on savages: “abilities important in carrying on one's daily life may be the very stuff of cognitive life. Just because they appear to us as bricolage is not sufficient reason to set them aside (or even down) as lower-level abilities unworthy of being considered important cognitive competencies in their own right” (p.289, italics in the original). In this paper, I suggested that if we transfer this way of thinking to the field of organizations, its usefulness will not be challenged. This suggests that bricolage should be added to the management and organization research agenda, where it is missing. As it is with the savages, as explained by Berry and Irvine, people in organizations may be doing it daily. 


\section{REFERENCES}

Alvesson, M. and Sveningsson, S. 2003. Managers doing leadership: The extraordinarization of the Mundane. Human Relations, 56: 1435-1459.

Baker, T., Miner, A.S., \& Eesley, D.T. 2003. Improvising firms: Bricolage, account giving and improvisational competencies in the founding process. Research Policy, 32: 255-276.

Barney, J.B. 1997. Gaining and sustaining competitive advantage. Reading, MA: Addison-Wesley.

Berry, J.W., \& Irvine, S.H. 1986. Bricolage: Savages do it daily. In R.J. Sternberg, \& R.K. Wagner (Eds.), Practical intelligence. Nature and origins of competence in the everyday world: 271-306. New York: Cambridge University Press.

Brown, S.L., \& Eisenhardt, K.M. 1997. The art of continuous change: Linking complexity theory and time-paced evolution in relentlessly shifting organizations. Administrative Science Quarterly, 42: 1-34.

Bruch, H., \& Ghoshal, S. 2002. Beware the busy manager. Harvard Business Review, February: 62-69.

Carlzon, J. 1985. Moments of truth. New York: HarperCollins.

Ciborra, C.U. 1999. Notes on improvisation and time in organizations. Accounting, Management and Information Technologies, 9: 77-94.

Ciborra, C.U. 2002. The labyrinths of information. Oxford: Oxford University Press.

Collis, D.J., \& Montgomery, C.A. 1995. Competing on resources. Harvard Business Review, July-August: 118-128.

Collins, J.C., \& Porras, J.I. 1996. Built to last. London: Century. 
Contu, A., \& Willmott, H. 2003. Re-embedding situatedness: The importance of power relations in learning theory. Organization Science, 14: 283-296.

Crossan, M.M., \& Berdrow, I. 2003. Organizational learning and strategic renewal. Strategic Management Journal, 24:1087-1105.

Cunha, M.P., Cunha, J.V., \& Kamoche, K. 1999. Organizational improvisation: What, when, how and why. International Journal of Management Reviews, 1: 299341.

Cunha, M.P., Kamoche, K., \& Cunha, R.C. 2003. Organizational improvisation and leadership: A field study in two computer-mediated settings. International Studies of Management \& Organization, 33(1): 34-57.

D’Aveni, R. 1994. Hypercompetition. New York: Free Press.

Daft, R.L. 1999. Leadership. Theory and practice. Fort Worth: Dryden Press.

Edmondson, A.C. 1999. Psychological safety and learning behavior in work teams. Administrative Science Quarterly, 44: 350-383.

Eisenhardt, K.M., \& Brown, S.L. 1999. Patching: Restitching business portfolios in dynamic markets. Harvard Business Review, May-June: 72-82.

Eisenhardt, K.M., \& Martin, J.L. 2000. Dynamic capabilities: What are they? Strategic Management Journal, 21: 1105-1121.

Feldman, M. 2004. Resources in emerging structures and processes of change. Organization Science, 15: 295-309.

Gabriel, Y. 1995. The unmanaged organization: Stories, fantasies and subjectivity. Organization Studies, 16: 477-501.

Gabriel, Y. 2003. Your home, my exile: Boundaries and “otherness” in antiquity and now. Organization Studies, 24: 619-632. 
Galunic, D.C., \& Eisenhardt, K.M. 2001. Architectural innovation and modular corporate forms. Academy of Management Journal, 44: 1229-1249.

Garud, R., \& Karnoe, P. 2003. Bricolage versus breakthrough: Distributed and embedded agency in technology entrepreneurship. Research Policy, 32: 277300.

Gildner, G. 1984. The spirit of entreprise. New York: Simon \& Schuster.

Gonzales, L. 2003. Deep survival: Who lives, who dies, and why. True stories of miraculous endurance and sudden death. New York: W.W. Norton.

Jacobson, R. 1992. The Austrian school of strategy. Academy of Management Review, 17: 782-807.

Jarzabkowski, P. 2004. Strategy as practice: Recursiveness, adaptation and practicesin-use. Organization Studies, 25: 489-520.

Kallinikos, J. 1998. Utilities, toys and make believe: Remarks on the instrumental experience. In R.C.H. Chia (Ed.), In the realm of organization. Essays for Robert Cooper: 163-187. Routledge, London.

Kamoche, K., \& Cunha, M.P. 2001. Minimal structures: From jazz improvisation to product innovation. Organization Studies, 22: 733-764.

Kamoche, K.N., Cunha, M.P., \& Cunha, J.V. (Eds.) 2002. Organizational improvisation. London: Routledge.

Katz, D., \& Kahn, R.L. 1978. The social psychology of organizations ( $2^{\text {nd }}$ ed.). New York: Wiley.

Lanzara, G.F. 1998. Self-destructive processes in institution building and some modest countervailing mechanisms. European Journal of Political Research, 33: 1-39. 
Lanzara, G.F. 1999. Between transient constructs and persistent structures: Designing systems in action. Journal of Strategic Information Systems, 8: 331-349.

Lengnick-Hall, C.A., \& Wolff, J.A. 1999. Similarities and contradictions in the core logic of three strategy research streams. Strategic Management Journal, 20: 1109-1132.

Levi-Strauss, C. 1966. The savage mind. Chicago: University of Chicago Press.

Lewin, A.Y. 1998. Jazz improvisation as a metaphor for organization theory. Organization Science, 9: 539.

Lippman, S.A., \& Rumelt, R.P. 2003. A bargaining perspective on resource advantage. Strategic Management Journal, 24: 1069-1086.

Lovas, B., \& Ghoshal, S. 2000. Strategy as guided evolution. Strategic Management Journal, 21: 875-896.

Mabert, V.A., Soni, A., \& Venkataramanan, M.A. 2001. Enterprise resource planning: Common myths versus evolving reality. Business Horizons, May-June: 69-76.

Mintzberg, H. 1973. The nature of managerial work. New York: Harper \& Row.

Mintzberg, H., \& McHugh, A. 1985. Strategy formation in an adhocracy. Administrative Science Quarterly, 30: 160-197.

Mintzberg, H, \& Westley, F. 2001. Decision making: It's not what you think. Sloan Management Review, 42(3): 89-93.

Moingeon, B., Ramanantsoa, B., Métais, E., \& Orton, J.D. 1997. Another look at strategy-structure relationships: The resource based view. Working paper, Groupe HEC, Jouy-en-Josas, France. 
Montuori, A. 2003. The complexity of improvisation and the improvisation of complexity: Social science, art and creativity. Human Relations, 56: 237-255.

Moorman, C., \& Miner, A.S. 1998. The convergence of planning and execution: Improvisation in new product development. Journal of Marketing, 62 (July): 120.

Nohria, N., \& Berkley, J.D. 1994. Whatever happened to the take-charge manager?. Harvard Business Review, January-February: 128-137.

O’Reilly, C.A., \& Tushman, M.L. 2004. The ambidextrous organization. Harvard Business Review, April: 74-81.

Orr, J. 1996. Talking about machines: An ethnography of a modern job. Ithaca, NY: Cornell University Press.

Pearson, A.E. 1989. Six basics for general managers. Harvard Business Review, JulyAugust: 94-101.

Perrow, C. 1986. Complex organizations: A critical essay (3rd ed.). New York: Random House.

Pfeffer, J., \& Salancik, G. 1978. The external control of organizations. New York: Harper \& Row.

Porter, M.E. 1981. The contributions of industrial organization to strategic management. Academy of Management Review, 6: 609-620.

Rerup, C. 2001. 'Houston, we have a problem': Anticipation and improvisation as sources of organizational resilience. Comportamento Organizacional e Gestao, 7: 27-44.

Scribner, S. 1986. Thinking in action: Some characteristics of practical thought. In R.J. Sternberg, \& R.K. Wagner (Eds.), Practical intelligence. Nature and 
origins of competence in the everyday world: 13-30. New York: Cambridge University Press.

Sewell, G. 1998. The discipline of teams: The control of team-based industrial work through electronic and peer surveillance. Administrative Science Quarterly, 43: 397-428.

Shane, S. 2000. Prior knowledge and the discovery of entrepreneurial opportunities. Organization Science, 11: 448-469.

Shenhav, Y. 1999. Manufacturing rationality. The engineering foundations of the managerial revolution. New York: Oxford University Press.

Sievers, B. 1993. Work, death and life itself. Essays on management and organization. Berlin: De Gruyter.

Sitkin, S.B. 1992. Learning through failure: The strategy of small losses. In B.M. Staw, \& L.L. Cummings (Eds.), Research in Organizational Behavior: Vol.14, 231-266. Greenwich, CT: JAI Press,.

Taylor, F.W. 1911. The principles of scientific management. New York: W.W.Norton.

Teece, D.J., Pisano, G., \& Shuen, A. 1997. Dynamic capabilities and strategic management. Strategic Management Journal, 18: 509-533.

Thayer, L. 1988. Leadership/communication: A critical review and a modest proposal. In G.M. Goldhaber, \& G.A. Barrett (Eds.), Handbook of Organizational Communication: 231-263. Ablex, Norwood, NJ.

Tsoukas, H., \& Knudsen, C. 2003. Introduction: The need for meta-theoretical reflection in organization theory. In H. Tsoukas, \& C. Knudsen (Eds.), The Oxford handbook of organization theory: 1-36. Oxford: Oxford University Press. 
Vera, D., \& Crossan, M. 2004. Theatrical improvisation: Lessons for organizations. Organization Studies, 25: 727-749.

Wagner, R.K. 2000. Practical intelligence. In R.J. Sternberg (Ed.), Handbook of intelligence: 380-395. New York: Cambridge University Press.

Watson, T.J. 1994. In search of management. London: International Thomson Business Press.

Weick, K.E. 1993. Organizational redesign as improvisation. In G.P. Huber, \& W.H. Glick (Eds.), Organizational change and redesign: 346-379. New York: Oxford University Press.

Weick, K.E. 1998. Improvisation as a mindset for organizational analysis. Organization Science, 9: 543-555.

Weick, K.E. 1999. The aesthetic of imperfection in orchestras and organizations. In M.P. Cunha, \& C.A. Marques (Eds.), Readings in Organization Science: 541563. Lisbon: ISPA.

Weick, K.E. 2003. Positive organizing and organizational tragedy. In K.S. Cameron, J.E. Dutton, \& R.E. Quinn (Eds.), Positive organizational scholarship: 66-80. San Francisco: Berrett Koehler.

Weick, K.E. 2004. Mundane poetics: Searching for wisdom on organization studies. Organization Studies, 25: 653-668.

Wernerfelt, B. 1984. A resource-based view of the firm. Strategic Management Journal, 5: 171-180. 


\section{APPENDIX}

Bricolage: Some practical illustrations

As illustrations, this Appendix presents five episodes collected from the management literature.

Episode 1. Nohria and Berkley (1994) advance the example of the director of a large telecommunications firm who was experimenting with creative uses of the computer resources of the company, while most companies were making huge investments in new technology. The director agreed that sooner or later the mainframes that stored data on the telecommunications network should be replaced. But the planning required for the replacement was significant and, in the meantime, the old mainframes should be kept in use, despite their limitations. Workstations were used to simulate the multi-million dollar information architecture that the company would have in the future, and the system-project time was cut from months to weeks. The creative use of an "inappropriate" resource was hence the source of significant gains at the moment of adopting the new technology.

Episode 2. Perhaps the most cited example of organizational bricolage is the case of Apollo 13 (e.g. Rerup, 2001): when an explosion threatened the survival of the three astronauts onboard, the unplanned solution was found not according to any kind of contingency plans but to bricolage: materials available on the spaceship (e.g. plastic bags, duct tape, etc.) were pieced together creatively, leading to an unorthodox but effective solution: "Swiggert [...] collected a pair of scissors, two of the command 
module's oversized lithium hydroxide canisters, and a roll of gray duct tape that was supposed to be used for securing bags of refuse to the ship's bulkhead in the final days of the mission. Haise dug out his book of LEM procedures and turned to the heavy cardboard pages that carried instructions for lifting off from the moon - pages he now had no use for at all - and removed them from their rings. Lovell opened the storage cabinet at the back of the LEM and pulled out the plastic-wrapped thermal undergarments he and Haise would have worn beneath their pressure suits while walking on the moon.” (Lovell \& Kluger, 1994: 276, in Rerup, 2001).

Episode 3. During a technology-mediated meeting of a cross-cultural product development team, a member with low computer literacy was able to solve an internet communication problem by writing messages on paper and displaying them in front of a web-camera, in order to perform a task set by the leader, but whose process had been left open. This might imply that when people feel confident enough to creatively exploit the available resources, improvisational leadership might be more appropriate than in situations where people are preoccupied with the adequacy of resources and with impression management (Cunha, Kamoche and Cunha, 2003). Simple and flexible resources may substitute for “proper” resources.

Episode 4. The development of wind turbines in Denmark followed what Garud and Karnoe (2003) described as a bricolage approach. This began with a low-tech design, ramping up progressively to prevail over the competing US approach: sophisticated, high-tech and pursuing a technological breakthrough. The authors explained the superiority of the bricolage approach as resting on the advantages of learning at the 
micro level by multiple agents involved in interactions that contributed to disperse knowledge throughout the sector. Adopting a "hands on" approach, working with the materials available and resorting to improvisational problem solving, the Danes were able to learn on an ongoing, incremental basis, that eventually proved to be more effective than the US “engineering science-based technology-push model” (p.284)

Episode 5. Founders of knowledge-intensive firms in Baker et al.’s (2003) study, tended to rely on their existing networks, i.e. on the available social resources, to staff the organization, to obtain financial resources and to seek management advice. Employees for engineering companies founded by academic researchers were recruited in the university department. The result was that the nascent firm lacked managerial skills in crucial areas, such as marketing and operations management. Even recognizing this limitation, scientists continued to rely on the existing network for recruitment. In other words, they worked with the "materials" that were available. The same pattern occurred when the entrepreneurs approached bankers to obtain financial resources: they tended to go first to the bank that initiated their home mortgage. Finally, when looking for managerial advice, they discussed problems with a "handy" group of people. One informant told researchers that he considered some of these people "pretty bad models" (Baker et al., 2003, p.267). Nevertheless, they still used them. These are all examples of what the authors called "network bricolage", i.e. making do with the available social network. 